Revista Brasileira de

Engenharia Agrícola e Ambiental

v. 13, n.4, p.406-410, 2009

Campina Grande, PB, UAEA/UFCG - http://www.agriambi.com.br

Protocolo 179.07 - 22/11/2007 • Aprovado em 05/01/2008

agriambi

\title{
Tolerância da cultura do pepino à salinidade em ambiente protegido ${ }^{1}$
}

\author{
Pedro R. F. de Medeiros', Sérgio N. Duarte ${ }^{3}$, Carlos T. S. Dias ${ }^{4}$
}

RESUMO

Neste trabalho se objetivou avaliar a cultura do pepino conduzido sobre condição salina, proveniente de sais fertilizantes, com seis níveis de salinidade do solo $\left(1,5 ; 2,5 ; 3,5 ; 4,5 ; 5,5\right.$ e $\left.6,5 \mathrm{dS} \mathrm{m}^{-1}\right) .0$ experimento foi conduzido na área experimental do Departamento de Engenharia Rural da ESALQ/USP, Piracicaba, SP. 0 plantio foi realizado em vasos utilizando-se solo arenoso. A época de plantio foi de 28/08/07 a 20/10/07. Como principais resultados, verificou-se que a produtividade máxima obtida foi $2,45 \mathrm{~kg} \mathrm{~m}^{-2}$ para o nível de salinidade $3,5 \mathrm{dS} \mathrm{m}^{-1}$; com os val ores de produção relativa obteve-se a salinidade limiar (SL) de 4,08 dS m-1, com uma queda de produção, após o ponto limiar na ordem de 19,33\% por dS $\mathrm{m}^{-1}$, para cada aumento de uma unidade de salinidade do solo.

Palavras-chave: extrator de solução, condutividade elétrica, produtividade relativa

\section{Tolerance of cucumber crop to salinity in greenhouse}

\begin{abstract}
The objective of this work was to evaluate the cucumber crop in saline conditions resulting from fertilizer salt, under six levels of soil salinity $\left(1.5,2.5,3.5,4.5,5.5\right.$ and $\left.6.5 \mathrm{dS} \mathrm{m} \mathrm{m}^{-1}\right)$. The study was carried out in the experimental area of the Department of Rural Engineering of the ESALQ/USP, Piracicaba/SP, Brazil. The planting was carried out in recipients using sandy soil during the period of 28/08/07 to 20/10/07. As the main results, it was verified that the maximum productivity was $2.45 \mathrm{~kg} \mathrm{~m}^{-2}$ for the salinity level of $3.5 \mathrm{dS} \mathrm{m}^{-1}$, that with the values of relative production the threshold salinity (SL) observed was of $4.08 \mathrm{dS} \mathrm{m}^{-1}$, and that there was a decline of $19.33 \%$ in production for unit increase of soil salinity above the threshold point.
\end{abstract}

Key words: solution extractor, electrical conductivity, relative productivity

\footnotetext{
1 Parte da Dissertação de Mestrado do primeiro autor, apresentada à ESALQ/USP - Piracicaba, SP

2 Pós-graduando em Irrigação e Drenagem, D epartamento de Engenharia Rural, ESALQ/USP. Av. Pádua Dias, 11. CP 9. CEP 13418-900, Piracicaba, SP. Fone: (19) 3371-5339, E-mail: prfmede@esalq.usp.br

3 DER/ESALQ/USP. Fone:(19) 3447-8543, E-mail: snduarte@esalq.usp.br

4 Departamento de Ciências Exatas/ESALQ/USP. Fone: (19) 3429-4127, ramal 215, E-mail: ctsdias@esalq.usp.br
} 


\section{INTRODUÇÃO}

O pepino tem apresentado importante crescimento na comercialização de hortaliças, haja vista ser bastante apreciado e consumido em todo o Brasil; em 2005 foram comercializados 41.187 Mg na Companhia de Entrepostos e Armazéns Gerais de São Paulo (CEAGESP) (FNP Consultoria \& Agroinformativos, 2005).

De acordo com o FNP Consultoria \& Agroinformativos (2005) a cultura se encontra entre as principais hortaliças cultivadas em estufa, ocupando o terceiro lugar em área cultivada dentre as culturas exploradas em casa de vegetação no Estado de São Paulo (Trani et al., 1997).

Segundo Fontes (2005) diversos fatores determinam a produtividade da cultura de pepino a qual é proporcional à duração do ciclo. Estes fatores são: estande, temperatura e não ocorrência de doenças que impeçam a extensão do ciclo cultural, além de fatores nutricionais e hídricos.

Em ambiente protegido a irrigação é essencial e, juntamente com a técnica da fertirrigacão, é primordial para obtenção das altas produtividades, mas, na maioria das vezes essas técnicas são empregadas de maneira inescrupulosa e inadequada, principalmente quando se trata do manejo inadequado da aplicação de sais fertilizantes no solo, como também do uso de águas de baixa qualidade.

A quantidade de sais adicionados ao solo via irrigação, é proporcional à quantidade de água aplicada, ou seja, a concentração de sais no solo cresce em função da lâmina de irrigação aplicada. Atualmente, a principal causa do aumento da salinização dos solos agrícolas tem sido as irrigações mal manejadas. O excesso de fertilização, o uso de água salina e a ausência de drenagem adequada, são fatores que resultam em situações desfavoráveis que podem favorecer a degradação de solos (Silva et al., 2008).

O uso de fertilizantes em excesso via água de irrigação em cultivos de olerícolas sob condições protegidas, eleva os níveis de salinidade do solo a ponto de superar os limites de tolerância pela maioria das culturas, refletindo-se na diminuição do rendimento; desta forma, a prática da fertirrigacão, embora contribua de maneira significativa para o aumento da produtividade em determinadas situações, sobretudo em ambientes protegidos, pode também resultar no acúmulo do teor salino no solo. $\mathrm{O}$ excesso de sais no solo reduz a disponibilidade de água às plantas além de exercer efeitos tóxicos de íons específicos sobre os processos fisiológicos e metabólicos das plantas e comprometer o rendimento e a qualidade da produção.

O monitoramento de íons no solo constitui-se em uma das principais ferramentas no manejo de fertirrigacão e tem sido realizado com base em amostragens de solo ou de solução do solo, por meio de extratores (Rhoades \& Oster, 1986).
Conforme Dias (2004) os valores de tolerância das culturas encontrados na literatura se referem aos níveis de salinidade ocasionados pelo uso de água salina; ressalta-se que a curva típica que relaciona o rendimento relativo com níveis crescentes de salinidade no solo, ocasionados por excesso de fertilizantes, não apresenta o mesmo comportamento daquelas determinadas para a salinização do solo com sais provindos de água de irrigação. Esta observação se deve ao fato de que um pequeno incremento de fertilizantes no solo pode acarretar em consumo extra de nutrientes pela cultura e conseqüente aumento de produtividade; entretanto, a partir de certo nível o potencial osmótico e os desequilíbrios nutricionais podem vir a reduzir os rendimentos.

Tendo em vista a falta de resultados científicos envolvendo a tolerância das culturas sobre a salinização ocasionada pelo excesso de fertilizantes propõe-se, neste trabalho, avaliar a cultura do pepino conduzida sobre condição salina proveniente de sais fertilizantes, com o manejo de fertirrigacão visando ao controle da salinidade do solo e seis níveis iniciais de salinidade $(1,5 ; 2,5 ; 3,5 ; 4,5 ; 5,5$ e 6,5 $\mathrm{dS} \mathrm{m}^{-1}$ ), sendo monitorados com cápsulas porosas sobre as variáveis de produção com vista a determinar, então, a sua salinidade limiar.

\section{MATERIAL E MÉTODOS}

O experimento foi conduzido na área experimental do Departamento de Engenharia Rural da Escola Superior de Agricultura "Luiz de Queiroz" - USP, no município de Piracicaba, SP. O material de solo utilizado foi de um perfil classificado como Latossolo Vermelho (EMBRAPA, 1999) fase arenosa, proveniente do campus da ESALQ e denominado Série "Sertãozinho" (Tabelas 1 e 2).

Tabela 1. Características físico-hídricas do solo utilizado

\begin{tabular}{|c|c|c|c|c|c|c|}
\hline CC & PMP & \multicolumn{3}{|c|}{ Frações Granulométricas (\%) } & \multirow{2}{*}{$\begin{array}{c}\text { Floculação } \\
(\%)\end{array}$} & \multirow{2}{*}{ Textura } \\
\hline & & Argila & Silte & Areia & & \\
\hline 0,31 & 0,09 & 25 & 4 & 71 & 92 & $\begin{array}{c}\text { Franco } \\
\text { arenosa }\end{array}$ \\
\hline
\end{tabular}

Realizou-se um único ciclo da cultura do pepino (Cucumis sativus L.) com duração de 58 dias, sendo que as plantas não se encontravam em senescência no final do período; a cultivar utilizada foi a Hokushin, enxertada sobre abóbora híbrida Excite-Ikki (Cucurbita spp); as mudas foram originárias de um viveirista especializado do Estado de São Paulo e o transplantio ocorreu no dia 23 de agosto de 2007 em vasos de 22,5 L, drenável na parte inferior; a irrigação utilizada foi por gotejamento, com vazão no emissor de $4 \mathrm{~L} \mathrm{~h}^{-1}$. Durante o ciclo da cultura registraram-se, em média temperaturas de 35,9 e 15, $7^{\circ}$

Tabela 2. Caracterização química do solo

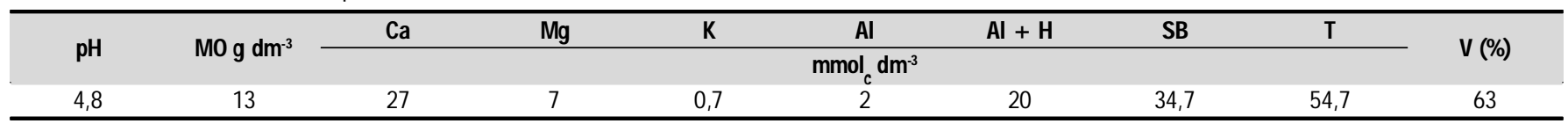


máxima e mínima respectivamente, juntamente com a variação da umidade de 61,0 e 39,7 \% medida às 9:00 e 15:00 h, respectivamente.

A estufa utilizada apresentava área total de $110 \mathrm{~m}^{2}$, pé direito 2,8 m, com sombrite nas laterais e nos fundos; as laterais possuíam cortinas que eram abertas pela manhã, fechadas no final da tarde e na ocorrência de chuvas, para evitar que a água atingisse as parcelas experimentais; em seu interior foram instalados mourões de madeira, os quais foram esticados e fixados a eles arame número 14 a 0,20 e 2,00 m de altura do solo no vaso; fez-se o tutoramento das plantas na vertical e se realizaram todos os tratos culturais, conforme Fontes (2005), visando ao pleno desenvolvimento da cultura.

Os seis níveis iniciais de salinidade do solo $(1,5 ; 2,5 ; 3,5$; 4,$5 ; 5,5$ e $6,5 \mathrm{dS} \mathrm{m}^{-1}$ ) se basearam em fertilizantes recomendados por Papadopoulos (1994) (Tabela 3).

Tabela 3. Solubilidade e índice de salinidade dos fertilizantes utilizados no experimento

\begin{tabular}{|c|c|c|c|}
\hline Fertilizantes & $\begin{array}{l}\text { Solubilidade } \\
\text { (g L-1 a } 20^{\circ} \mathrm{C} \text { ) }\end{array}$ & Índice parcial & Índice global \\
\hline Nitrato de cálcio & 1.200 & 52,5 & 4,41 \\
\hline Nitrato de potássio & 310 & 73,6 & 11,58 \\
\hline Nitrato de amônia & 1.900 & 69,0 & 3,25 \\
\hline Fosfato monopotássico & 230 & 34,3 & 0,64 \\
\hline Sulfato de potássio & - & 46,1 & 0,85 \\
\hline Sulfato de magnésio & 500 & - & - \\
\hline
\end{tabular}

O manejo da fertirrigação teve como objetivo controlar o nível de salinidade inicial do solo durante todo o ciclo, o que só foi possível, inicialmente com a construção de uma curva de salinização artificial do solo que se relaciona com a concentração dos fertilizantes e com a condutividade elétrica desejada, partindo-se da equação de Richards (1954) (Eq. 1).

$$
\mathrm{C}=640 \mathrm{CEs}
$$

em que:

C - concentração de sais fertilizantes, $\mathrm{mg} \mathrm{L}^{-1}$

CEs - condutividade elétrica da solução, dS m${ }^{-1}$

$\mathrm{O}$ valor da concentração final de fertilizantes na água $(\mathrm{Cf})$ aplicada ao solo, necessário para se obter os níveis de CEes desejados, foi estimado com base nos níveis de salinidade desejados e as proporções de fertilizantes, corrigido pela umidade de saturação (Eq. 2).

$$
\mathrm{Cf}=\frac{\mathrm{Us}}{\mathrm{Ucc}} \mathrm{Ci}
$$

em que:

Cf - concentração final de fertilizantes na solução salinizante, $\mathrm{mg} \mathrm{L}^{-1}$

Us - umidade da pasta saturada, $\mathrm{g} \mathrm{g}^{-1}$

Ucc - umidade do solo a capacidade de campo, $\mathrm{g} \mathrm{g}^{-1}$

G - concentração de fertilizantes com base na curva de salinização construída na etapa anterior, $\mathrm{mg} \mathrm{L}^{-1}$
$\mathrm{Na}$ estufa as parcelas eram representadas por uma planta, distribuídas (sorteadas) em quatro blocos, cada um considerado uma repetição. $\mathrm{O}$ delineamento estatístico adotado foi o de blocos casualizados completos com quatro repetições. Em cada vaso foi instalado um tensiômetro e um extrator de cápsula porosa, utilizados para quantificar a água existente e extrair a solução do solo, respectivamente. As irrigações foram realizadas quando a tensão nos tensiômetros atingia 20 $\mathrm{kPa}$ e somente durante o tempo necessário para que a umidade do solo retornasse à capacidade de campo $(5 \mathrm{kPa})$ evitando, assim, a perda de sais por lixiviação, com o auxílio da curva característica de retenção de água no solo. Nos extratores se aplicava vácuo a uma tensão de $80 \mathrm{kPa}$, seis horas após realizada a irrigação para extração da solução do solo, sendo esta solução levada para o laboratório a fim de quantificar a condutividade elétrica com o auxílio de um condutivímetro digital. Quando a condutividade elétrica entre as irrigações variava $10 \%$ acima do valor inicial, aplicava-se apenas água.

A partir da Eq. 4, proposta por Maas \& Hoffman (1977), foi possível calcular a salinidade limiar (SL) da cultura do pepino.

$$
\mathrm{Y}=100-\mathrm{b}(\mathrm{CEes}-\mathrm{SL})
$$

em que:

$$
\begin{aligned}
& \text { Y - rendimento potencial, } \% \\
& \text { CEes - salinidade do extrato de saturação, } \mathrm{dS} \mathrm{m} \mathrm{m}^{-1} \\
& \mathrm{SL} \text { - salinidade limiar da cultura, } \mathrm{dS} \mathrm{m} \mathrm{m}^{-1} \\
& \text { b - diminuição do rendimento por aumento unitário } \\
& \quad \text { de salinidade acima do valor } \mathrm{SL}, \%\left(\mathrm{dS} \mathrm{m} \mathrm{m}^{-1}\right)^{-1}
\end{aligned}
$$

\section{RESULTADOS E DISCUSSÃO}

Obteve-se, a partir das Eq(s). 1 e 2, uma curva artificial de salinização do solo (Figura 1), com boa correlação $\mathrm{R}=0,976$ entre a concentração de sais e a CEes do solo permitindo, desta forma, se estimar a quantidade de sais a ser aplicado ao solo com a finalidade de se obter a condutividade elétrica desejada no extrato de saturação; e com o auxílio da curva e a utilização de extratores do solo, foi possível controlar e monitorar (Figura 2) a condutividade elétrica da solução do solo.

\section{Produção e salinidade limiar}

Vários fatores influenciam a produtividade da cultura do pepino, quais sejam: estande, temperatura e a não ocorrência de doenças que impedem a extensão do ciclo da cultura, além de fatores nutricionais e hídricos. Observou-se efeito quadrático significativo $(\mathrm{p}<0,01)$ dos níveis iniciais de salinidade do solo sobre a produção comercial (PCOM) e total (PTOT), número comercial de frutos (NCOM) e total (NTOT) e ainda efeito linear significativo ( $\mathrm{p}<0,01)$ para os comprimentos comercial $(\mathrm{CCOM})$ e total (CTOT) (Tabela 4).

(Fontes, 2005) relata que em ambiente protegido, dependendo do período do ano, da variedade e do sistema de con- 


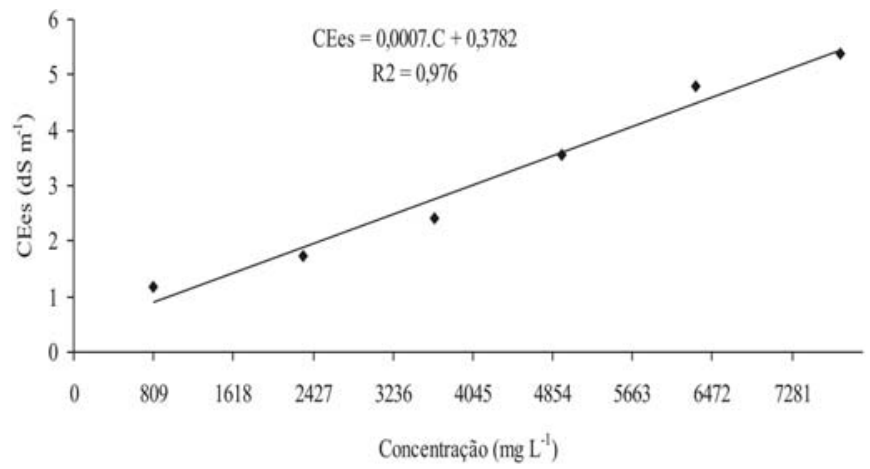

Figura 1. Curva de salinização artificial relacionando-se a concentração dos sais fertilizantes aplicados via água de irrigação e a CEes

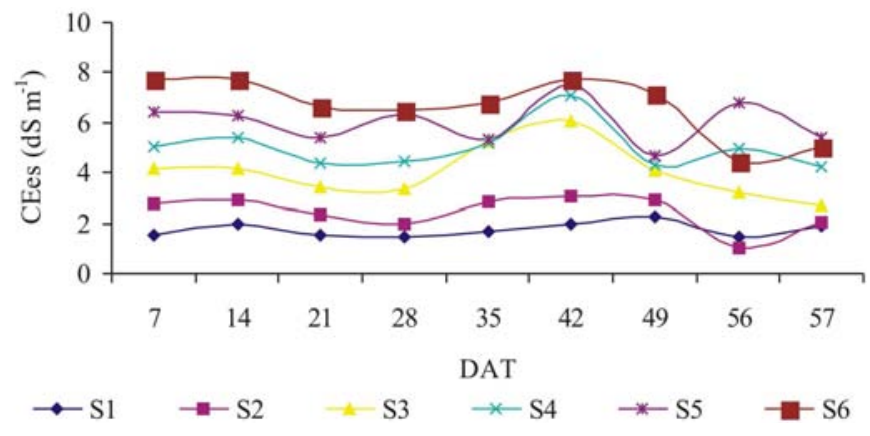

Figura 2. Valores de condutividade elétrica do extrato de saturação do solo estimados a partir dos valores medidos na solução obtida por extratores de cápsula porosa ao longo do ciclo

Tabela 4. Resumo da análise de variância da produção comercial de frutos (PCOM), produção total de frutos (PTOT), número comercial de frutos (NCOM) e número total de frutos (NTOT), para a cultura do pepino, em função dos níveis de salinidade

\begin{tabular}{lcccc}
\hline \multirow{2}{*}{ Fator } & \multicolumn{4}{c}{ Estatística $\mathbf{~}$} \\
\cline { 2 - 5 } \multicolumn{1}{c}{} & PCOM & PTOT & NCOM & NTOT \\
Salinidade & $11,11^{* *}$ & $12,98^{* *}$ & $8,37^{* *}$ & $11,21^{* *}$ \\
Linear & $2,96^{\text {ns }}$ & $0,15^{\text {ns }}$ & $0,01^{\text {ns }}$ & $0,71^{\text {ns }}$ \\
Quadrática & $48,57^{* *}$ & $56,22^{* *}$ & $35,83^{* *}$ & $42,18^{* *}$ \\
CV (\%) & 23,93 & 15,97 & 26,18 & 17,24 \\
\hline
\end{tabular}

ns Não significativo a nível de 0,05 de probabilidade pelo teste $\mathrm{F}$; ${ }^{* *}$ Significativo a nível de 0,05 de probabilidade pelo teste $\mathrm{F}$

dução, a produtividade pode atingir $20,56 \mathrm{~kg} \mathrm{~m}^{-1}$ para as estações de outono-inverno, com densidades de 4,76 plantas $\mathrm{m}^{-2}$.

Considerando-se o espaçamento de 0,5 entre plantas e 1,2 $\mathrm{m}$ entre fileiras, a densidade foi de 1,6 plantas $\mathrm{m}^{-2}$. O rendimento máximo obtido foi de $2,45 \mathrm{~kg} \mathrm{~m}^{-2}$ para o nível de salinidade $\mathrm{S} 3=3,5 \mathrm{dS} \mathrm{m}^{-1}$, ficando a produtividade obtida abaixo da encontrada na literatura devido, basicamente, a alguns fatores, como a duração do ciclo que foi de 58 dias, o cultivo ter sido em vasos, temperaturas diárias elevadas e umidade relativa diária fora da faixa recomendada para a cultura.

Mas, independentemente dos fatores climáticos adversos, a cultura apresentou aumento gradativo na sua produtividade (g por planta) com 26 DAT (início da colheita) até os 40 DAT, diferenciando-se, a partir daí, entre os níveis de salinidade.
Na Figura 3 se encontram as análises de regressão das médias para todas as variáveis respostas: produção comercial (PCOM) e total (PTOT), número comercial (NCOM) e total (NTOT) e comprimentos comercial (CCOM) e total (CTOT), relacionando-as com os níveis de salinidade estudados demonstrando, independente da variável resposta analisada, uma superioridade dos níveis intermediários de salinidade do solo.
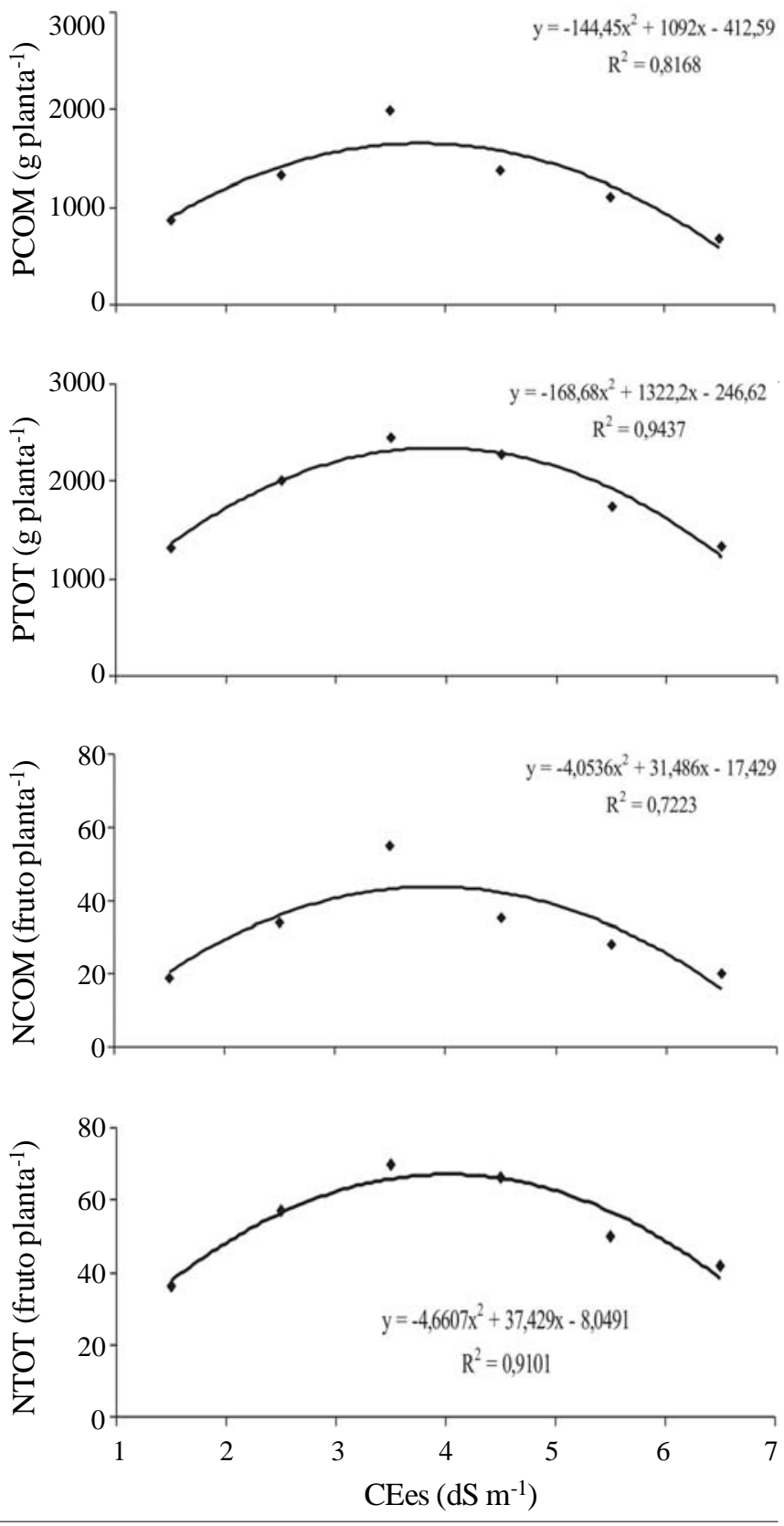

Figura 3. Curvas de regressão para as médias da produção comercial (PCOM), produção total (PTOT), número comercial de frutos ( $\mathrm{NCOM}$ ) e número total de frutos (NTOT), em função dos níveis de salinidade do solo

Os principais efeitos nocivos dos sais nos vegetais se caracterizam pela redução e não uniformidade do crescimento, presença de coloração verde-azulada e queimadura nas bordas das folhas das plantas, além de manchas desnudas no solo (Richards, 1954); confirma-se, assim, o motivo pelo 


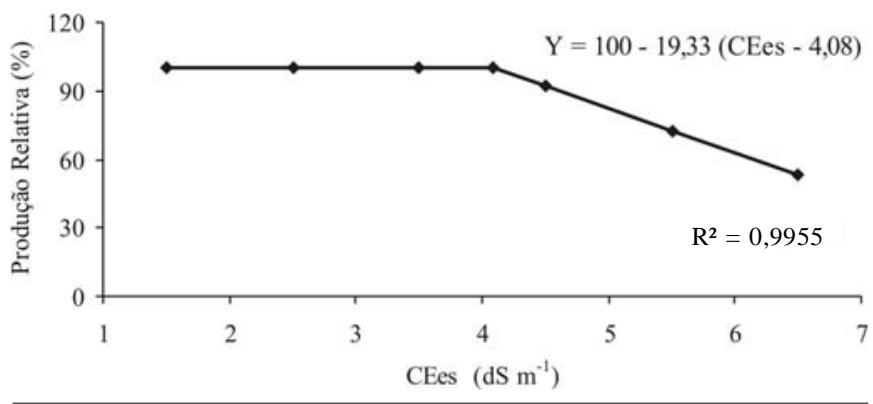

Figura 4. Produção relativa da cultura do pepino em função da salinidade do solo

qual algumas plantas apresentaram desuniformidades no crescimento e queimadura nas bordas das folhas.

A tolerância das culturas a salinidade pode ser definida como a capacidade da planta em suportar determinados níveis de sais, presentes na solução do solo, sem a ocorrência de perdas significativas de seus rendimentos e qualidade de produção agrícola, quando comparados com aqueles sob condições não salinas (Maas, 1990).

Calculou-se, a partir da equação 3, a salinidade limiar (SL) com base na produção relativa para a cultura do pepino, que foi da ordem de 4,08 $\mathrm{dS} \mathrm{m}^{-1}$ (Figura 4); na literatura, a salinidade limiar (SL) da cultura do pepino é de $2,5 \mathrm{dS} \mathrm{m}^{-1}$ demonstrando, assim, maior tolerância da cultura a salinidade, que pode estar associada a diversos fatores como, por exemplo, ao uso de mudas enxertadas.

Segundo Oda (1995), a enxertia proporciona maior tolerância das culturas a salinidade e aumenta a capacidade de absorção de água e nutrientes; outros fatores relevantes se referem ao uso da irrigação por gotejamento e ao fato dos sais utilizados serem provenientes de fertilizantes.

Blanco (1999) obteve redução na produção total e comercial de 6,71 e $7,24 \%$ e a de número de frutos, 7,58 e $8,04 \%$, respectivamente, para o aumento de uma unidade de salinidade do extrato de saturação; esses valores estão abaixo daquele indicado por Maas \& Hoffman (1977) ao afirmarem que a redução na produção é da ordem de $13 \%$ para o aumento de uma unidade de salinidade do solo. Posteriormente, Maas (1990) observa redução na produção de $6,9 \%$. No estudo se observa uma redução na produção, da ordem de $19,33 \%$, para cada aumento de uma unidade de salinidade do solo, estando este valor acima dos valores citados.

\section{CONCLUSÕES}

1. Os níveis inicias de salinidade do solo estudados afetaram, realmente, a cultura do pepino para as condições em referência.

2. A cultura apresentou valores satisfatórios nas suas variáveis respostas para o nível de salinidade do solo, de $3,5 \mathrm{dS} \mathrm{m}^{-1}$.
3. A cultura apresentou valores elevados de salinidade limiar e redução da produção em percentagem, por aumento de uma unidade de salinidade.

\section{AGRADECIMENTOS}

À Fundação de Amparo à Pesquisa do Estado de São Paulo (FAPESP), pelo total auxílio financeiro à pesquisa ensejando, assim, a possibilidade de realização deste trabalho.

\section{LITERATURA CITADA}

Blanco, F. F. Tolerância do pepino enxertado à salinidade em ambiente protegido e controle da salinização do solo. Piracicaba: ESALQ/USP, 1999. 104p. Dissertação Mestrado

Dias, N. S. Manejo da fertirrigacão e controle da salinidade em solo cultivado com melão rendilhado sob ambiente protegido. Piracicaba: ESALQ/USP, 2004. 110p. Tese Doutorado

EMBRAPA - Empresa Brasileira de Pesquisa Agropecuária. Centro Nacional de Pesquisa de Solos. Sistema brasileiro de classificação de solos. Brasília: Embrapa Produção de Informação, 1999. 412p.

FNP Consultoria \& Agroinformativos. Pepino. In: Agrianual 2005: Anuário da agricultura brasileira. São Paulo: Argos Comunicação, 2005. 546p.

Fontes, P. C. R. Olericultura: Teoria e prática. 1.ed. Viçosa, MG; 2005. 486p.

Maas, E. V. Crop salt tolerance. In: Tanji, K. K. (ed.) Agricultural salinity assessment and management manual. New York: ASCE, 1990. chap. 13, p. 262-304.

Maas, E. V.; Hoffman, G. J. Crop salt tolerance - Current assessment. Journal of Irrigation and Drainage Division, v.103, n.IR2, p.115-134, 1977.

Oda, M. New grafting methods for fruit-bearing vegetables in Japan. Japan Agricultural Research Quarterly, v.29, n.3, p.187-194, 1995.

Papadopoulos, A. P. Growing greenhouse seedless cucumbers in soil and in soilless média. Ottawa: Agriculture Canada Publication, 1994. 126p.

Rhoades, J. D.; Oster, J. D. Solute content. In: Klute, A. (ed.) Methods of soil analysis. 2 nd. ed. Madison: ASA/SSSA, 1986. part 1., p.995-1006. Monograph 9

Richards, L. A. Diagnostico y rehabilitacion de suelos salinos y sodicos. México: Departamento de Agricultura de los Estados Unidos de América, 1954. 172p. Manual de Agricultura, 60

Silva, M. O.; Freire, M. B. G. S.; Mendes, A. M.; Freire, F. J.; Sousa, C. E. S.; Góes, G. B. Crescimento de meloeiro e acúmulo de nutrientes na planta sob irrigação com águas salinas. Revista Brasileira de Engenharia Agrícola e Ambiental. v.12, n.6, p.593-605, 2008.

Trani, P. E.; Groppo, G. A.; Silva, M. C. P.; Minami, K.; Burke, T. J. Diagnóstico sobre a produção de hortaliças no estado de São Paulo. Horticultura Brasileira, v.15, n.1, p.19-24, 1997. 